MICE Note-208

\title{
The Design of a Rapid Discharge Varistor System For the MICE Magnet Circuits
}

\author{
Michael A. Green \\ Lawrence Berkeley Laboratory, Berkeley CA 94720, USA
}

23 July 2008*

\begin{abstract}
The need for a magnet circuit discharge system, in order to protect the magnet HTS leads during a power failure, has been discussed in recent MICE reports [1], [2]. In order to rapidly discharge a magnet, one has to put enough resistance across the lead. The resistance in this case is varistor that is put across the magnet in the event of a power outage. The resistance consists of several diodes, which act as constant voltage resistors and the resistance of the cables connecting the magnets in the circuit to each other and to the power supply. In order for the rapid discharge system to work without quenching the magnets, the voltage across the magnets must be low enough so that the diodes in the quench protection circuit don't fire and cause the magnet current to bypass the superconducting coils. It is proposed that six rapid discharge varistors be installed across the three magnet circuits the power the tracker solenoids, which are connected in series. The focusing magnets, which are also connected in series would have three varisitors (one for each magnet). The coupling magnets would have a varistor for each magnet. The peak voltage that is allowed per varistor depends on the number of quench protection diodes that make up the quench protection circuit for each magnet coil circuit. It is proposed that the varistors be water cooled as the magnet circuits are being discharged through them. The water cooling circuit can be supplied with tap water. The tap water flows only when the varistor temperature reaches a temperature of $45 \mathrm{C}$.
\end{abstract}

\section{TABLE OF CONTENTS}

$\begin{array}{lr}\text { Abstract } & 1 . \\ \text { The Basic Design Parameters for the Varistor Circuits } & 2 . \\ \text { Rapid Discharge Varistor Systems for the MICE Tracker Magnets } & 6 . \\ \text { Rapid Discharge Varistor Systems for the MICE Coupling Magnets } & 9 . \\ \text { Rapid Discharge Varistor Systems for the MICE Focusing Magnets } & 11 . \\ \text { The effect of the Rapid Discharge System on the Magnet Power Cables } & 15 . \\ \text { Some Concluding Comments } & 18 . \\ \text { Acknowledgements } & 19 . \\ \text { References } & 19 .\end{array}$

* Last revision 31 August 2008 


\section{The Basic Design Parameters for the Varistor Circuits}

All of the MICE magnets will be quench protected by sub-dividing the magnet coils and putting a resistor and back to back diodes across the coil sub-division [3]. The MICE cooling channel has three types of magnets; 1) tracker magnets, 2) coupling magnets, and 3) focusing magnets. The rapid discharge varistor system is designed to bring the current in the magnets down rapidly in the event of a power failure [4]. This is so that the tops of the HTS leads don't get to warm and cause them to burn out. Figure 1, shows the HTS leads of a MICE tracker magnet. In the picture one can see the leads for the match coils (a total of four $300 \mathrm{~A}$ leads) and the leads for the spectrometer part of the magnet (two 300 A leads and two 60 A leads).

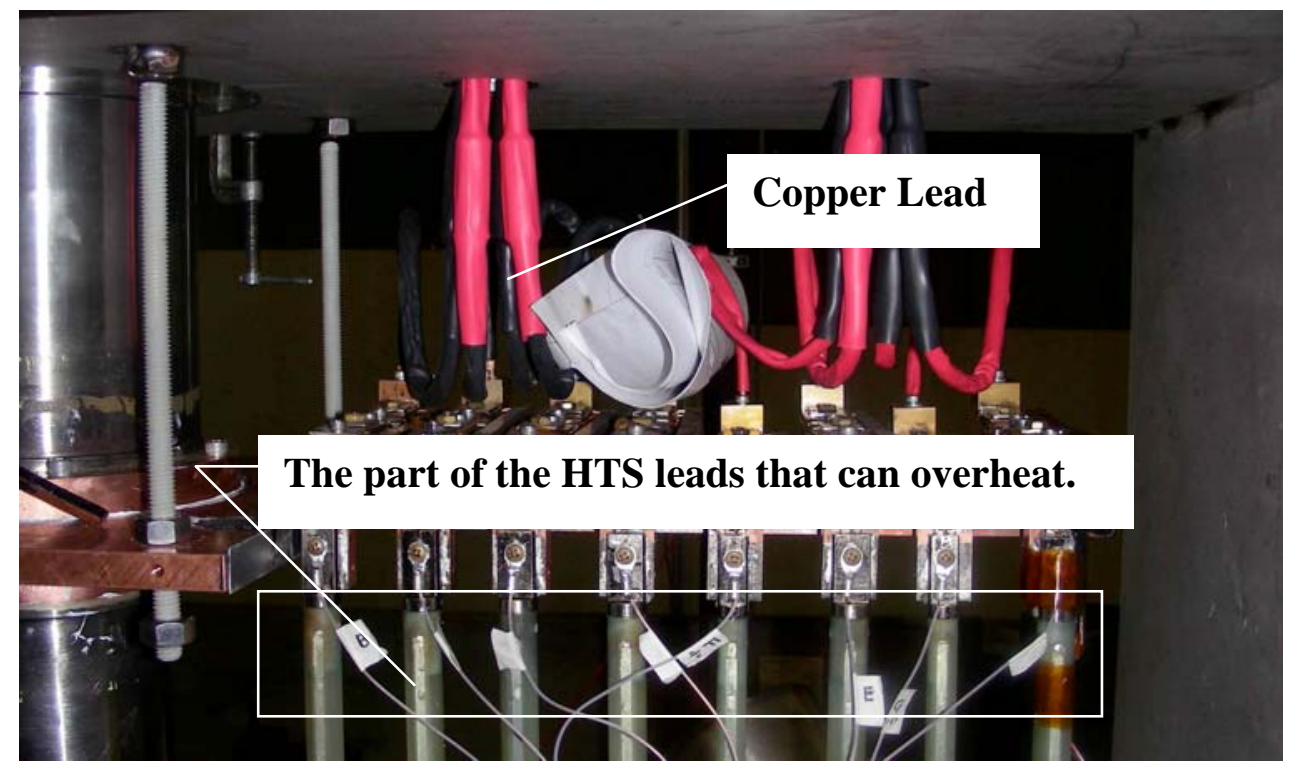

Figure 1. The Top of the HTS leads, and the Copper Leads for the MICE Tracker Magnet It is important to keep the top of the HTS leads (the area of the HTS leads that is in the box) from getting too warm.

The full configuration of MICE will have two tracker magnets (some prefer to call them spectrometer magnets). During earlier stages of the experiment there will be one tracker magnet. For quench protection, the three-coil spectrometer magnet will be sub-divided into four parts. Each of the match coils (M1 and M2) will have its own diode and resistor across the coil. The tracker solenoids will be connected in series. The M1 coil of one tracker solenoid will be connected in series with the M1 coil of the other; the M2 coil of one tracker solenoid will be connected in series with the M2 coil of the other; and the three coil spectrometer solenoid (E1, center and E2) of one tracker magnet will be connected to the three coil spectrometer solenoid of the other tracker magnet The $60 \mathrm{~A}$ tuning power supplies will also be connected in series. The tracker magnet has six 300 A leads and two 60 A leads that go to room temperature (These leads are in Figure 1). The maximum current in the magnet in the $300 \mathrm{~A}$ is expected to be a bit more than $275 \mathrm{~A}$. The current in the tracker magnet system does not change much with momentum changes in the MICE cooling channel.

The full configuration of MICE will have two coupling magnets. During earlier stages of the experiment there will be fewer than two coupling magnets. For quench protection, each coupling magnet has eight sub-divisions of the magnet coil. Each coupling magnet will have its 
own power supply. The coupling magnet has only two leads that go to room temperature. The maximum current in the magnet (at $\mathrm{p}=240 \mathrm{MeV} / \mathrm{c}$ ) is expected to be a bit more than $210 \mathrm{~A}$. The current in the coupling magnet is proportional to the momentum of the muon in the MICE cooling channel. The coupling magnet current is lower in the non-flip mode.

The full configuration of MICE will have three focusing magnets. During earlier stages of the experiment there will be fewer than three focusing magnets. For quench protection, each focusing magnet has two sub-divisions of the magnet coil. For the most part, all of the focusing magnets will be connected in series to a power supply. The focusing magnet has four leads (a pair for each coil) that go to room temperature. This permits the focusing magnet to be connected in either the flip mode (with the coils at opposite polarity) or the non-flip mode (with the two coils at the same polarity). The maximum current in the magnet is expected to be a bit more than $250 \mathrm{~A}$ (when the magnet operates in the flip mode at $\mathrm{p}=240 \mathrm{MeV} / \mathrm{c}$ ). The current is the non-flip mode is lower. The current in the focusing coil is proportional to the muon momentum in the MICE cooling channel.

The maximum charging or discharging voltage of a MICE magnet is determined by the number of diodes (cold or warm) in the quench protection circuit. The design voltage in the forward direction for the quench protection circuit is assumed to be 4 volts for a cold power diode. If this diode is at room temperature, the forward voltage is of the order of 1 volt. As a cold diode carries current in the forward direction, its forward voltage will go down. This is a temperature phenomena that will be explained later in this report. As a warm diode carries current, its forward voltage will go up because there is a resistive component to diode forward voltage. In general, the resistive component of the forward voltage out weighs the temperature component of the forward voltage when a diode starts out at room temperature. When the quench protection diodes are at $4 \mathrm{~K}$, the charging and discharging voltage for a magnet can't exceed 4 volts times the number of quench protection diodes across the magnet coil. When the quench protection diodes are room temperature, the charging and discharging voltage for a magnet can not exceed the number of diodes in the quench protection system times 1 volt. In general, the charge or discharge voltage should be limited to about three quarters of the firing voltage for a cold or warm quench protection diodes (about 3 volts per diode when it is at $4 \mathrm{~K}$ and 0.75 volts per quench diode when it is at room temperature). For the coupling magnet, the maximum charge or discharge voltage should not exceed about 24 volts, because the coupling coil will use cold diodes in the quench protection system.

For a single focusing magnet, the charging or discharging voltage should not exceed 6 volts (when the diodes are cold). When the quench protection system is warm, the number of diodes in the circuit should be increased by a factor of four for the same charging and discharging voltage limit. For two focusing magnets in series, the maximum charging or discharging voltage should not exceed 12 volts. For three focusing magnets in series, the maximum charging or discharging voltage should not exceed about 18 volts. The voltage on the 300 A power supply should be limited to about \pm 6 volts when one focusing magnet is being powered. In the other two cases the magnet power supply can be operated at the full \pm 10 volts.

The tracker magnet use diodes at $4 \mathrm{~K}$ for the quench protection system. For a single spectrometer coil set for a tracker magnet, the charging or discharging voltage should not exceed about 12 volts. For two-spectrometer coil sets in series, the maximum charging or discharging voltage is 24 volts. In all cases, the power supply can operate at $\pm 10 \mathrm{~V}$. For a single match, the voltage limit for a charge or a discharge is 3 volts. For two match coils in series (M1 with M1 and M2 with M2), the maximum charge or discharge voltage for the 300 A power supply should 
be no more than \pm 6 volts. The 300 A power supplies for the tracker solenoid match coils should be set to a maximum voltage of $\pm 3 \mathrm{~V}$ when a single magnet is operated and \pm 6 volts when both magnets are operated in series.

Table 1 shows the basic design parameters of the quench protection and fast discharge circuits for the three types of MICE magnets.

Table 1. An Estimate Amount of Copper needed to keep the Upper End of the HTS Leads Cold during a Fast Discharge, when AC Loss and Static Heat load Helium Boil Off are considered and not considered

\begin{tabular}{lccccc}
\hline \hline \multicolumn{1}{c}{ Parameter } & AFC & Coupling & M1 & M2 & E1+C+E2 \\
\hline Magnet Self Inductance (H) & 98.6 & 580 & 11.0 & 5.0 & $\sim 74.0$ \\
Number of Magnet Turns & 19304 & 15704 & 5040 & 3332 & 23606 \\
Magnet Charge Time (s) & 7540 & 14530 & 1800 & 750 & 4620 \\
Magnet Charging Voltage (V) & 3.0 & 8.5 & 2.0 & 2.0 & 4.5 \\
Coupling Coefficient to Mandrel & 0.8 & 0.9 & 0.8 & 0.82 & 0.85 \\
Charging AC Loss Heat Load (W) & 0.65 & 0.66 & & $\sim 1.2$ & \\
Rapid Discharge AC Loss Heat Load (W) & 2.25 & 3.64 & & 4.42 & \\
Design Static Heat Load at 4.2 K (W) & 2.7 & 1.5 & & 2.7 & \\
Time for a Rapid Discharge (s) & 3600 & 5400 & & 1800 & \\
Magnet Fast Discharge Voltage (V) & 6.28 & 22.9 & 2.0 & 0.8 & 11.8 \\
Number of Quench Diode Packs & 2 & 8 & 1 & 1 & 4 \\
Discharge Voltage per Diode Pack (V) & 3.14 & 2.78 & $\sim 2.0$ & $\sim 0.8$ & 2.95 \\
Average Copper Lead Heat Flow (W) & 36 & 16 & 18.7 & 18.7 & 22.6 \\
Maximum He Lead Cooling (W) & 50.8 & 56.9 & & 78.6 & \\
Net Heat Flow to the HTS Leads (W) & -14.8 & -40.9 & & -18.6 & \\
Heat to the Copper (kJ) & -53.3 & -220.9 & & -10.4 & \\
Copper $\Delta$ H from 64 K to 76 K (J g ${ }^{-1}$ ) & 2.5 & 2.5 & & 2.5 & \\
Copper Mass Needed with Cooling (kg) & 0 & 0 & & 0 & \\
Copper Mass Needed w/o Cooling (kg) & 51.8 & 34.6 & & 43.2 & \\
\hline \hline
\end{tabular}

Figure 2 shows the forward voltage characteristics of a silicon power diode as a function of temperature [5] [6]. The shape of the curve shown in Figure 1 is very much like the forward voltage characteristic of Lake Shore silicon diode temperature sensors. A typical temperature diode has a forward voltage (at $10 \mu \mathrm{A}$ ) at $4.2 \mathrm{~K}$ that is eight times the forward voltage measured at $293 \mathrm{~K}$. Power diodes appear to have the same factor of eight forward-voltage ratio (at $4.2 \mathrm{~K}$ as compared to the forward voltage at $293 \mathrm{~K}$ ). We know that the forward voltage for silicon diode temperature sensors changes when the diode is in a magnetic field [7]. The change in the forward voltage depends on the field direction with respect to the diode junction. We also know that when the field is removed, the voltage may not quite go back to the same forward voltage that was seen before the magnetic field was applied to the diode.

The actual $4.2 \mathrm{~K}$ forward voltage for the actual diodes used must be grater than the 4 volts used for the design calculations. One should base the design of the rapid discharge system design on measurements of the forward diode voltage at $4.2 \mathrm{~K}$ and at $300 \mathrm{~K}$. The forward voltage for the diodes will be measured by ICST in Harbin at $4.2 \mathrm{~K}, 77 \mathrm{~K}$, room temperature. The magnetic field dependence of diode forward will be measured with the field parallel to the diode junction and perpendicular to the diode junction. 


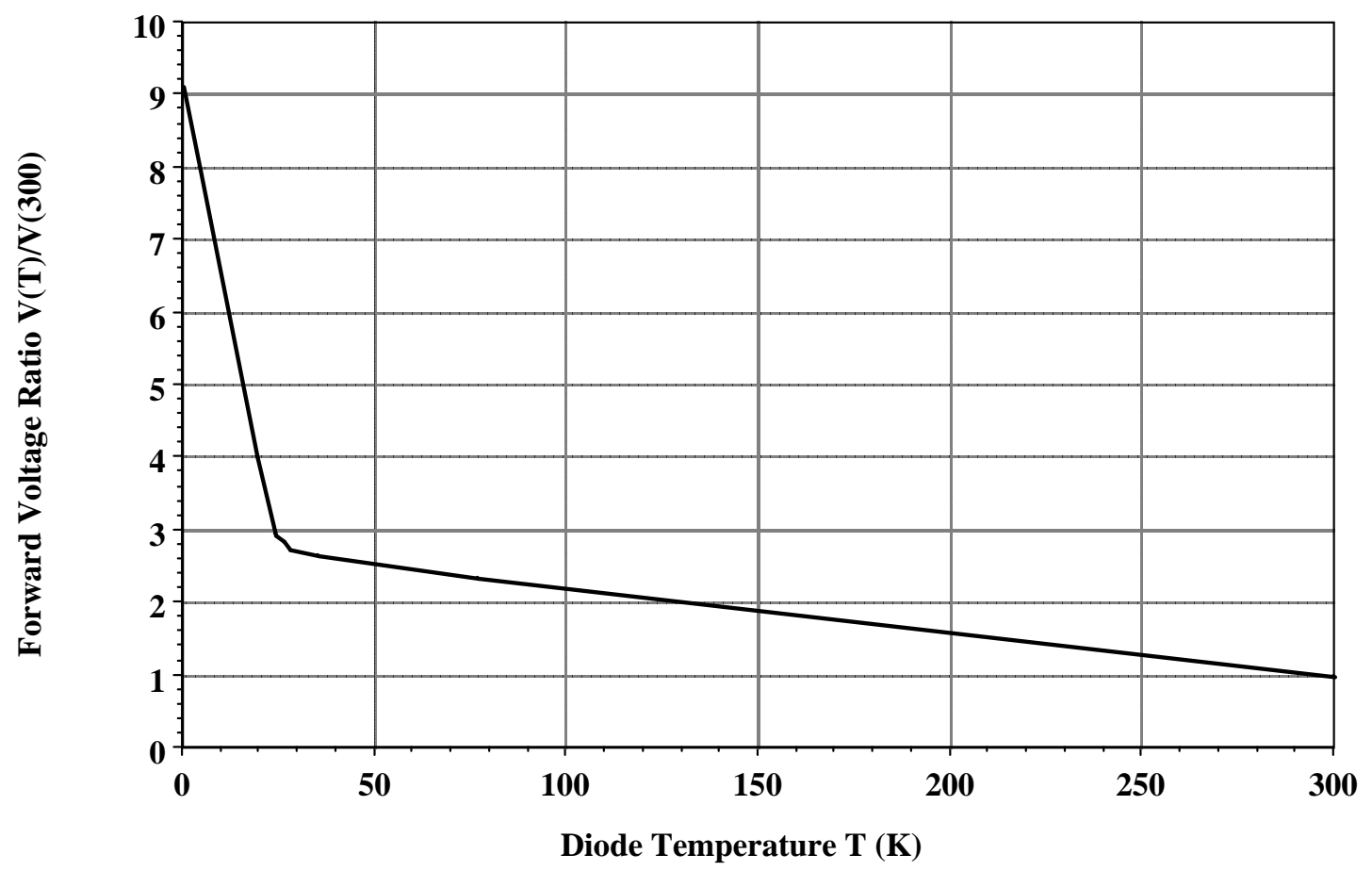

Figure 2. The Forward Voltage Ratio versus Temperature for Silicon Diodes from $2 \mathrm{~K}$ to $400 \mathrm{~K}$ (The forward voltage ratio is one at $293 \mathrm{~K}$. At $4.2 \mathrm{~K}$, the forward voltage ratio is about eight.)

It is known that the forward voltage of a typical power diode can be about 1 volt at room temperature $(293 \mathrm{~K})$. When the power diode carries $200 \mathrm{~A}$, the forward voltage goes up to about $1.4 \mathrm{~V}$. Some of these diodes can carry up to $1000 \mathrm{~A}$, but room temperature the forward voltage will increase to between 1.7 and $1.8 \mathrm{~V}$. In the reverse direction these diodes will carry a current of a few milliamps when the voltage in the reverse direction is $100 \mathrm{~V}$. Heating of power diodes affects their forward voltage. The forward voltage at $400 \mathrm{~K}$ will be about 50 percent of the forward voltage at $293 \mathrm{~K}$. In general, power diodes should not be used at temperatures above $170 \mathrm{C}(443 \mathrm{~K})$. As a result, the diodes used for a rapid discharge system must be cooled. The rapid discharge diodes for the tracker solenoid will be water cooled only when the diodes are carrying enough current to cause diode heating.

The forward voltage in a diode is proportional to the diode junction thickness [8]. Power diodes have a junction thickness that is about 3.3 times thickness than the diodes typically used for temperature sensors. The design forward voltage of $4 \mathrm{~V}$ for the quench protection diode appears to be to be quite conservative. If the actual forward voltage is $8 \mathrm{~V}$ at $4.2 \mathrm{~K}$, the magnet quench protection diodes won't fire at a forward voltage of $4 \mathrm{~V}$ until the diode temperature reaches about $18 \mathrm{~K}$. If the actual forward voltage for the quench protection diodes is $6 \mathrm{~V}$, the temperature at which the diodes fire at 4 volts will be about $11 \mathrm{~K}$. Since the quench protection diodes may not be connected directly to a source of liquid helium, it is useful to design the diode system to operate in the temperature range from 7 to $10 \mathrm{~K}$. 


\section{Rapid Discharge Varistor Systems for the MICE Tracker Magnets}

The power and quench protections circuits for a tracker magnet is shown in Figure 2 [9]. Each match coil is quench protected using a cold diode and resistor across it in order to reduce the voltage buildup in the coil. The three spectrometer coil set (end coil 1, the center coil and end coil 2), which generated the uniform field for the tracker is subdivided into four parts. Each end coil is quench protected by a cold resistor and diode. The center coil is subdivided into two parts. Each part has a cold diode and resistor across it. The first subdivision of the center coil consists of the inner ten layers of the coil. The second sub-division of the center coil consists of the outer ten layers of the coil. The subdivision of the tracker solenoid in this way is designed to limit the peak voltage to ground to about $1400 \mathrm{~V}$. The peak layer-to-layer voltage in the tracker solenoid is about $140 \mathrm{~V}$.

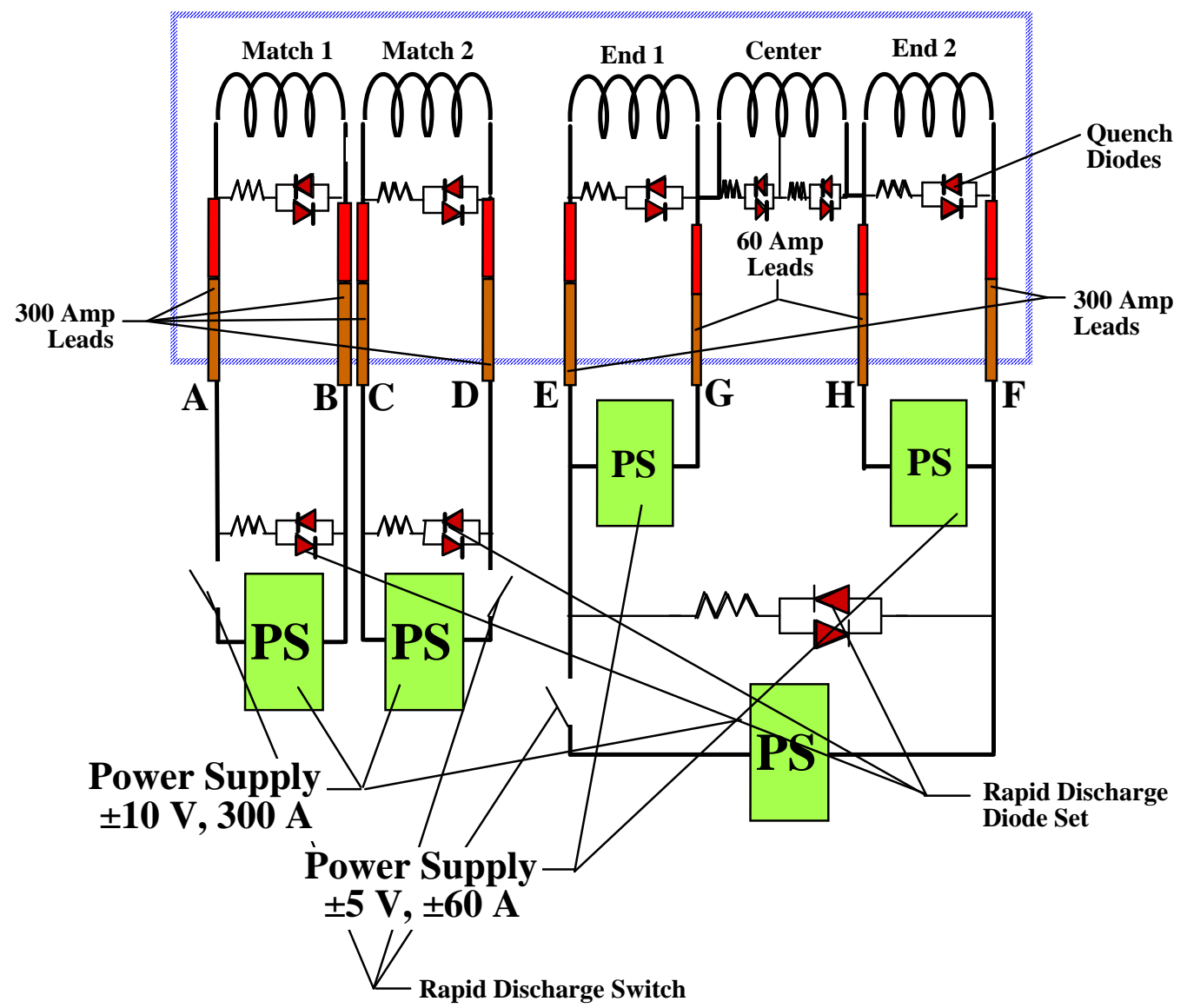

Figure 3. The Magnet Power and Quench Protection System for a Single Tracker Magnet

In Figure 3 the quench protection resistors are shown as cold back-to-back diodes in series with cold resistors. Back-to-back diodes are installed so that the magnet coils can operate at either polarity. The resistance of the resistor that is series with the cold diodes is small $\sim 10 \mathrm{~m} \Omega$, so little of the magnet stored energy is dissipated within the resistor during the quench. The rapid discharge varistor is shown as a single back-to-back diode and resistor. The varistor part of the rapid discharge system is two or more diodes in a circuit that is designed to act in both directions. 
A circuit diagram for the varistor rapid discharge system for the three-coil spectrometer part of the magnet (shown as back to back diodes plus a resistor in Figure 2) is shown in Figure 4. Since the spectrometer part of the tracker magnet has four sub-divisions with cold diodes the warm rapid discharge varistor is shown with 13 diodes (two more than the 11 diodes needed to safely discharge the magnet). The extra two diodes ensure that the spectrometer magnet can be operated in either polarity. Figure 5 shows the rapid discharge varistor for the match coils M1 and M2. The varistor circuit is shown with six diodes that are in three back-to-back diode pairs. No rapid discharge system is needed for the 60 A circuits. All diodes are attached to a watercooled aluminum plates. The plates have machined grooves that carry the water with an aluminum cover plate that seals the water circuit. The diode cooling must come from an uninterruptible source (treated water from a $1 \mathrm{~m}^{3}$ header tank in the UK). Water flow starts when to power fails or when the aluminum plates get too hot. In order to remove 3.66 MJ from a tracker magnet about 25 liters of water are required (with $\Delta \mathrm{T}=40 \mathrm{C}$ )

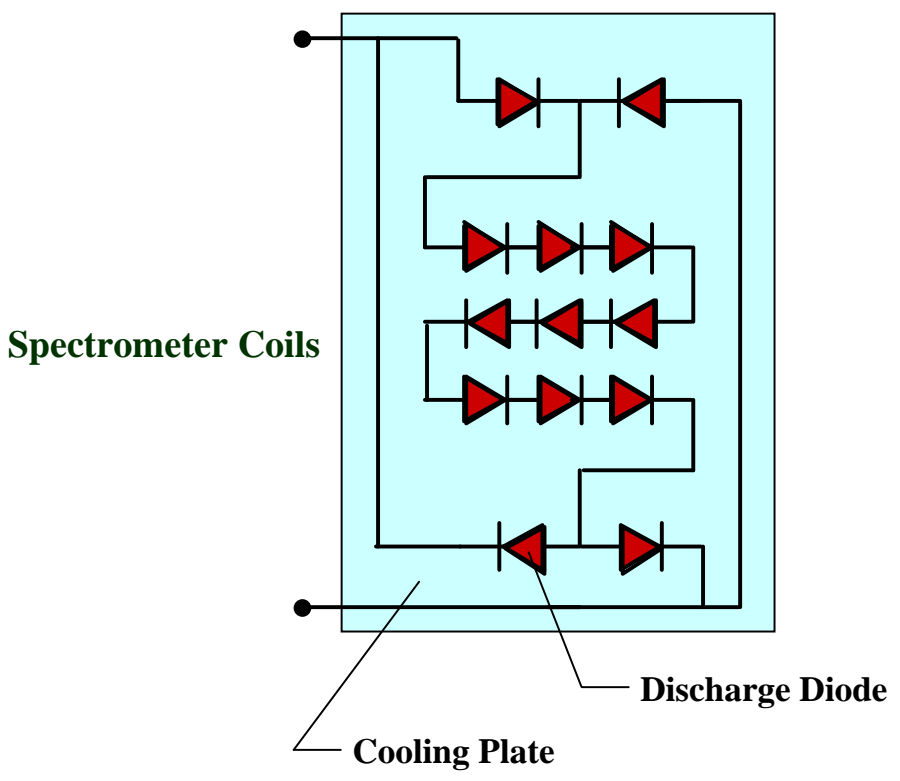

Figure 4. The Rapid Discharge Circuit for the Three-Coil Spectrometer Part of the Tracker Magnet

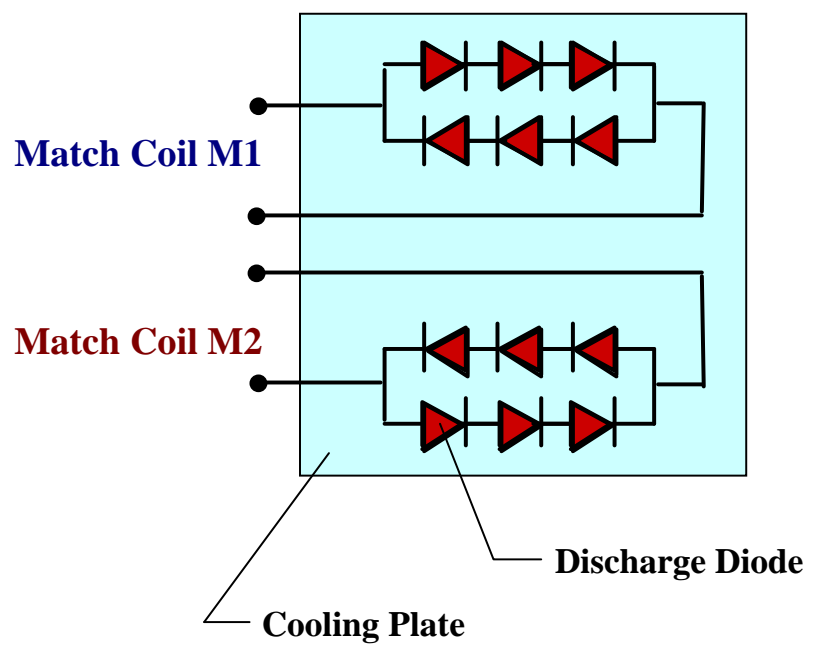

Figure 5. The Rapid Discharge Circuit for the Tracker Magnet Match Coils (one circuit for each match coil) 
There are a rapid discharge circuits for each of the two tracker magnets. There are two match coil rapid discharge circuits for each of the tracker magnets. Since the tracker magnets will be operated separately in stages 2 and 3 of MICE, the rapid discharge circuits for the two tracker magnets must be separated. The second set of rapid discharge circuits will be in the second rack that will be shipped with the second tracker magnet.

Match coil 1 of tracker magnet 1 will be connected in series with match coil 1 of tracker magnet 2. Match coil 2 of tracker magnet 1 will be connected in series with match coil 2 of tracker magnet 2. The spectrometer coils set of tracker magnet 1 will be connected in series with the spectrometer coil set of tracker magnet 2. Figure 8 shows the connection of the two tracker magnets [10]. The rapid discharge diode sets shown in Figure 8 are two of the circuits shown in Figures 6 and 7 that are hooked in series. Exactly how the magnets are connected together depends on the MICE stage and whether the experiment is the flip or non-flip mode.

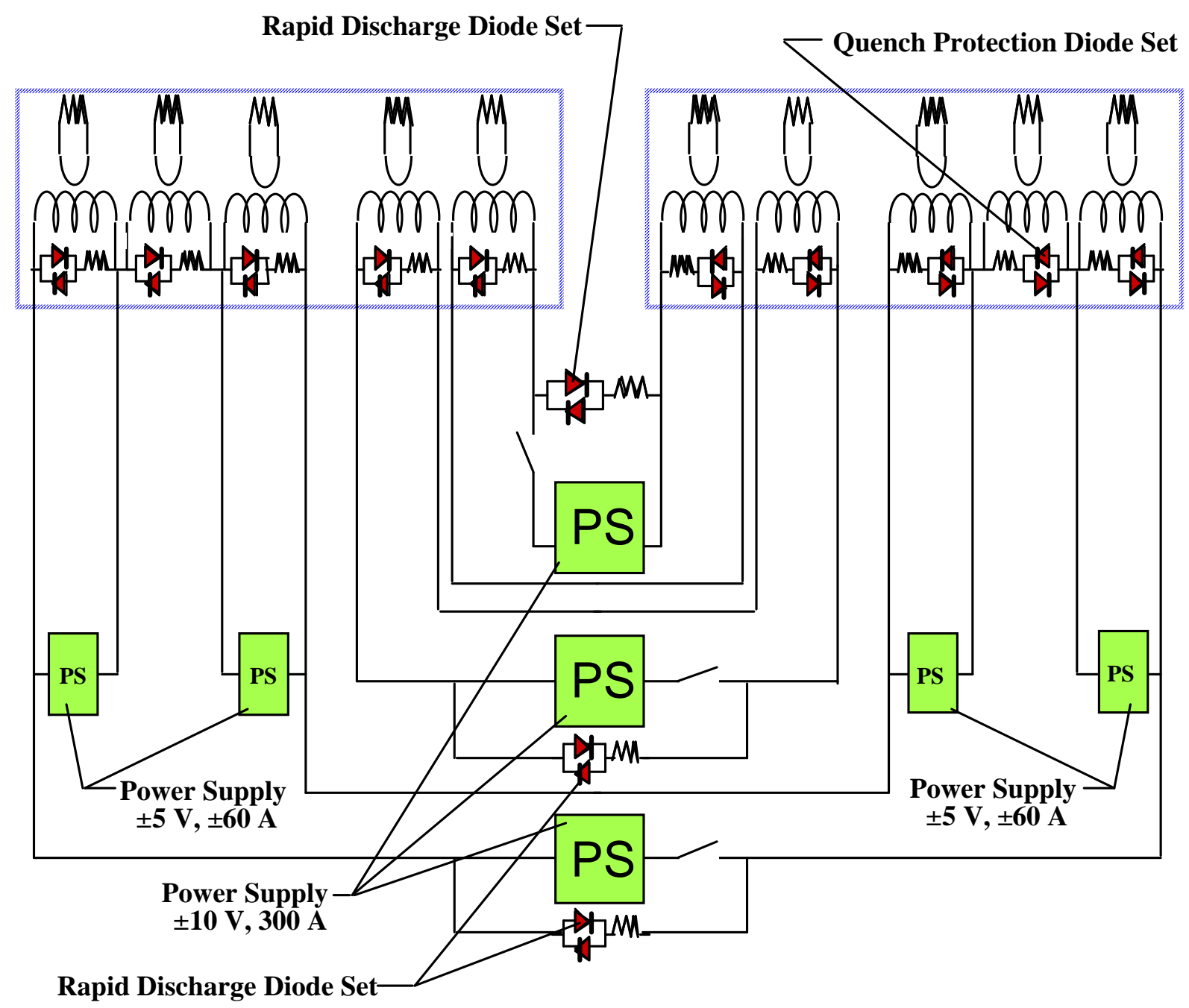

Figure 6. The Magnet Circuits for the Two Tracker-Magnets When They are Connected in Series (The two tuning circuits that carry current form the 60 A supplies are likely to be connected in series.) 


\section{Rapid Discharge Varistor Systems for the MICE Coupling Magnets}

Figure 7 shows the power and quench protection circuits for a coupling magnet [11]. The coupling magnet is subdivided into eight parts for quench protection [12]. Each part has a cold diode and resistor across it. The first subdivision of the center coil consists of the inner twelve layers of the coil. The second sub-division of the center coil consists of the next twelve layers of the coil and so until all 96 layers of the coil have a resistor and diode across them. The subdivision of the tracker solenoid in this way is designed to limit the peak voltage to ground to about $2600 \mathrm{~V}$ (when the resistor resistance is about $50 \mathrm{~m}$. The peak layer-to-layer voltage in the tracker solenoid is about $430 \mathrm{~V}$.

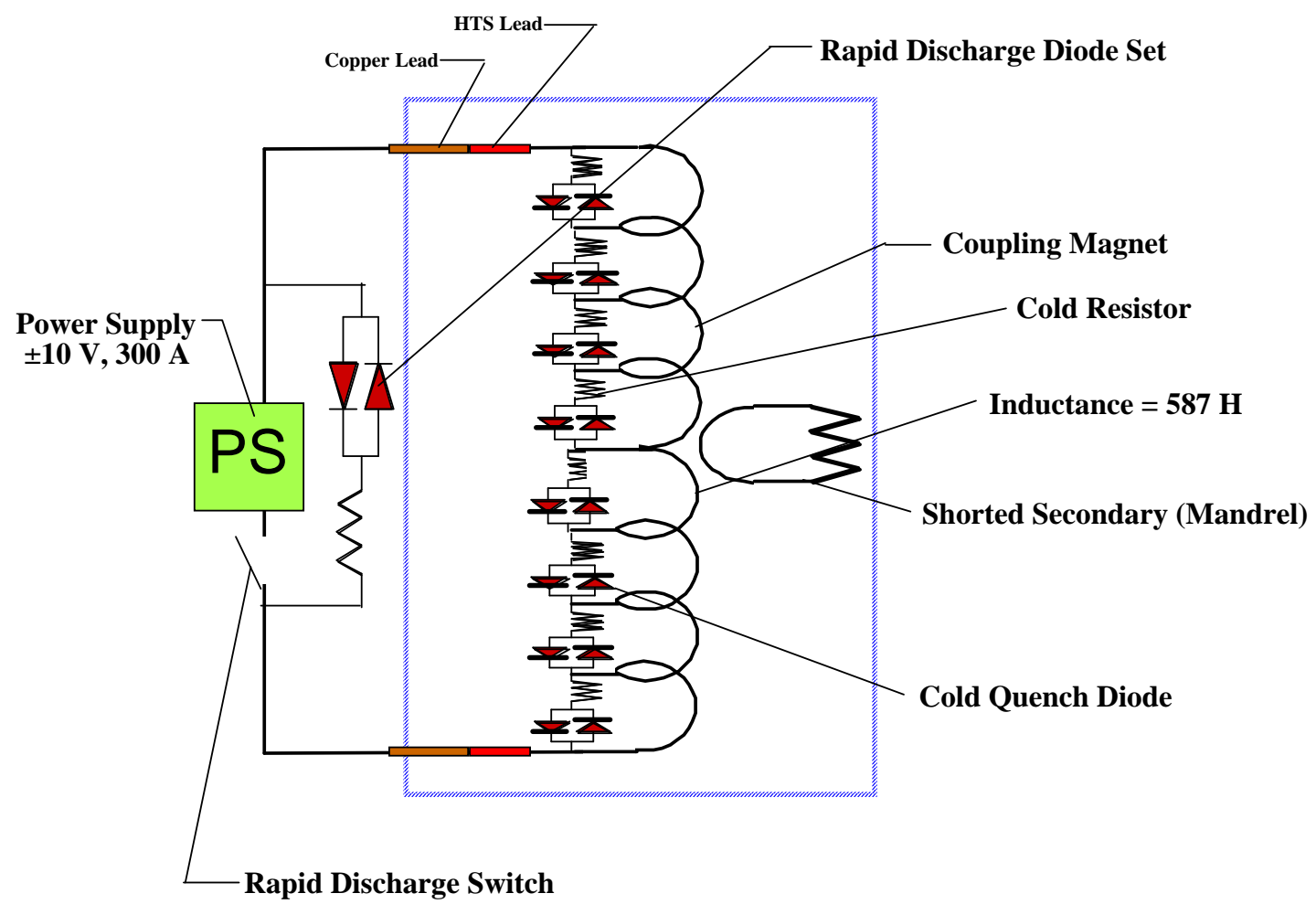

Figure 7. The Magnet Power and Quench Protection System for a Single Coupling Magnet

In Figure 7 the quench protection resistors are shown as cold back-to-back diodes in series with cold resistors. (The quench protection diodes and resistors are shown inside the dashed line that indicates the cold part of the superconducting magnet circuit. Back-to-back diodes are installed so that the magnet coils can operate at either polarity. The resistance of the resistor that is series with the cold diodes is small $\sim 50 \mathrm{~m} \Omega$, so very little of the magnet stored energy is dissipated within the quench protection diodes and resistor over the time that a magnet quench occurs.

If a cold resistor of 5 ohms per subdivision where to be used to protect the coupling magnet, the mass of the eight resistors would have to be about $63 \mathrm{~kg}$ (about $7.8 \mathrm{~kg}$ per resistor) in order for the resistor to extract half of the magnet stored energy and not reach a temperature of $80 \mathrm{C}$ at the end of the quench. Putting 5 ohms across each sub-division would reduce the peak voltage to ground to about $1300 \mathrm{~V}$ and it would reduce the peak layer-to-layer voltage to $215 \mathrm{~V}$. 
A circuit diagram for the varistor rapid discharge system for the coupling magnet (shown as back to back diodes plus a resistor in Figure 7) is shown in Figure 8. Since the coupling magnet has eight sub-divisions with cold diodes the warm rapid discharge varistor is shown with twentyfive diodes (two more than the twenty-three diodes needed to safely discharge the magnet). The extra two diodes ensure that the coupling magnet can be operated in either polarity.

All of the rapid discharge diodes are attached to a water-cooled aluminum plates. The plates have machined grooves that carry the water with an aluminum cover plate that seals the water circuit. The diode cooling must come from an un-interruptible source. (This can be tap water in the US or it can treated water from the same $1 \mathrm{~m}^{3}$ header tank that must be used in the UK). The flow of water flow starts either when to power fails (with about 30 second delay) or when the aluminum cooling plates get too hot (say above $50 \mathrm{C}$ ).

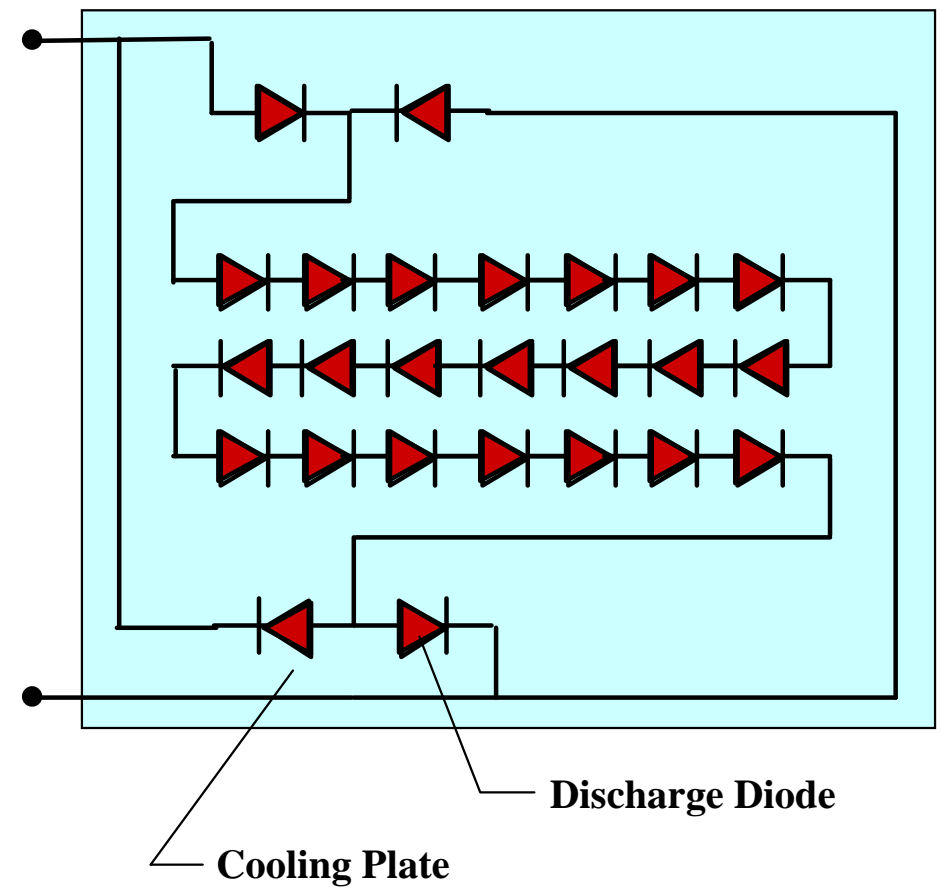

Figure 8. The Rapid Discharge Circuit for a Single MICE Coupling Magnet

The coupling magnet rapid discharge system is shown in Figure 10. The rapid discharge diodes could be mounted on two Aluminum plates with a cooling circuit between them. The rapid discharge system shown in Figure 8 is designed to discharge the coupling magnet in about 5400 seconds at the $240 \mathrm{MeV} / \mathrm{c}$ current for the coupling magnet with MICE operating in the flip mode. The peak heating in twenty-three diodes is about $5 \mathrm{~kW}$ (about $217 \mathrm{~W}$ per diode). The total amount of cooling water need to absorb the $13 \mathrm{MJ}$ of stored magnetic energy in the coupling magnet is about 80 liters (assuming a $40 \mathrm{C}$ rise in the water temperature and controlling the flow off of the cooling plate temperature. The water needed to cool a single coupling coil represents about 30 percent of the total water need to cool the rapid discharge systems for all of MICE magnets. It is estimated that 270 liter of cooling water is needed for a rapid discharge for all of the MICE magnets (assuming a $40 \mathrm{C}$ rise in the water temperature).

Each coupling magnet will have its own 300 A power supply. The two 300 A power supplies and the two rapid discharge diode system will fit in less than one rack. It is estimated that three racks will be needed for all of the MICE power supplies and discharge systems. 


\section{Rapid Discharge Varistor Systems for the MICE Focusing Magnets}

Each focusing magnet consists of two coils, which have their leads brought out to room temperature [13]. This permits the focusing magnet to be connected in the flip mode (with the two coils at opposite polarity) or in the non-flip (mode where the fields are of the same polarity. In the flip mode, the field on axis is zero at the center of the magnet. In the non-flip mode the field is relatively uniform along the axis. The focusing magnet operates at its highest current when the magnets are operated in the flip mode.

The power and quench protections circuits for all three focusing magnets connected in series is shown in Figure 9. The magnet is sub-divided between the coils. There is no sub-division within a magnet coil. As shown in Figure 11, the subdivision diodes and resistors are cold. Since the resistance of the resistors is low (up to $50 \mathrm{~m} \Omega$ ), not much of the magnet stored energy ends up in the resistor and diodes (perhaps less than $50 \mathrm{~kJ}$ ends up in the resistors. The subdivision of the focusing solenoid in this way is designed to limit the peak voltage to ground to about $2500 \mathrm{~V}$. The peak layer-to-layer voltage in the tracker solenoid is less than $100 \mathrm{~V}$ when the magnet is operated in the flip mode at a muon momentum $240 \mathrm{MeV} / \mathrm{c}$.

The total inductance is from $304 \mathrm{H}$ to $416 \mathrm{H}$, but there is no inductive coupling between the AFC magnets.

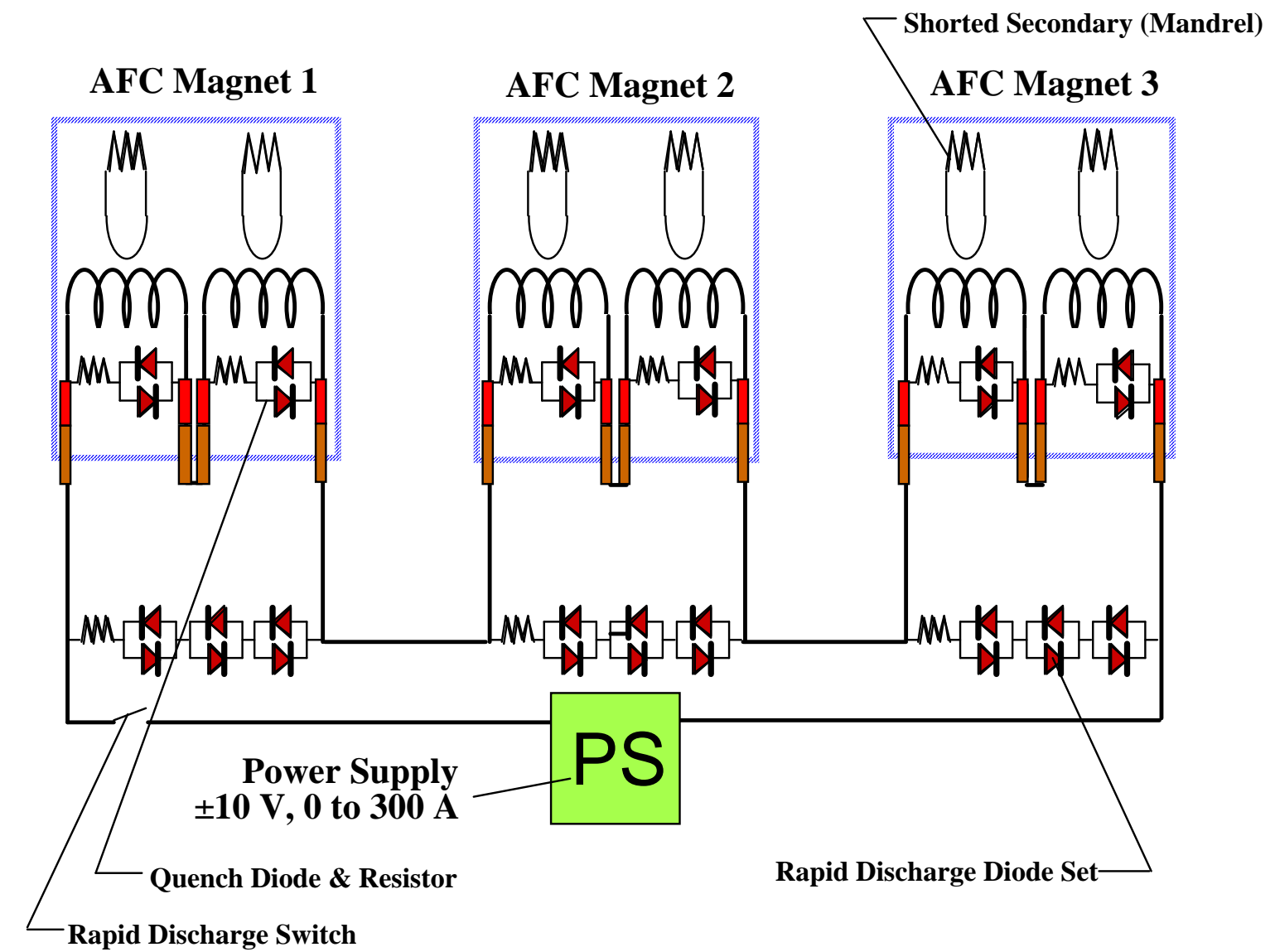

Figure 9. The Magnet Power and Quench Protection System for Three-focusing Magnets in Series 
Quench protection of the focusing magnet system is strongly dependent on quench back from the mandrel particularly when the three magnets are in series. There is virtually no inductive coupling between one focusing magnet and another. The two coils within a coupling magnet are strongly coupled. Quench back is the only way that the string of coupling magnets can go normal when one of the magnets in the string becomes normal. Resistance in the magnet circuit in any magnet induces currents to flow in the mandrels of all of the magnets. When the mandrel reaches $10 \mathrm{~K}$, the coil wound on the mandrel will quench through quench back.

The rapid discharge resistor shown in Figure 9 is shown as three back-to-back diode is series with a resistor, which is a combination of cable resistance and diode resistance as they carry current. The actual rapid discharge varistor consists of eight diodes that form a system that is equivalent to six pairs of back-to back diodes. Figure 10 shows the design for a rapid discharge varistor that will discharge the focusing magnet in about 3600 seconds. There are three such packages hooked in series for the magnet circuit shown in Figure 9. It is proposed that there will be rapid discharge varistor for each focusing magnet in MICE. Since the focusing magnets are added to the MICE channel one by one, this approach makes sense. In stage 6 of MICE where there will be three focusing magnets, the three rapid discharge system would end up in series as shown in the circuit in Figure 9.

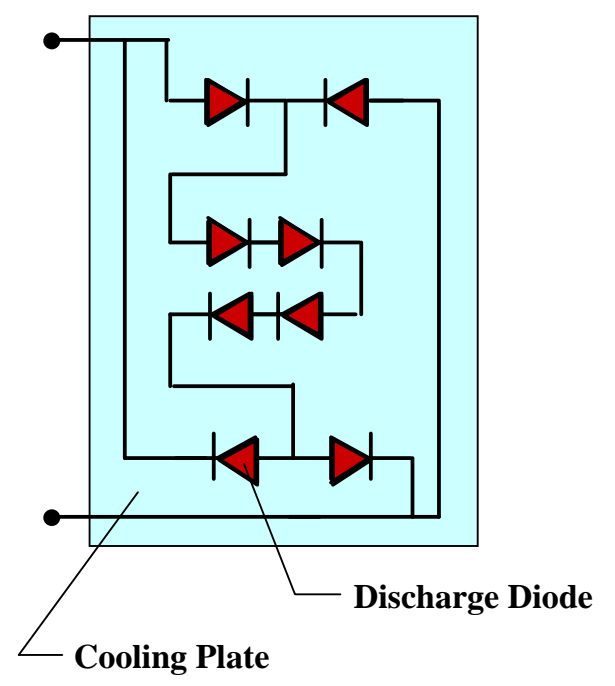

Figure 10. The Rapid Discharge Circuit for a Single MICE focusing Magnet

The focusing magnet rapid discharge system is shown in Figure 12. The rapid discharge diodes for the magnets mounted can be mounted on an Aluminum plate with a cooling circuit machined into the plate. The rapid discharge system shown in Figure 12 is designed to discharge the coupling magnet in about 3600 seconds at the $240 \mathrm{MeV} / \mathrm{c}$ current for the coupling magnet with MICE operating in the flip mode. The peak heating in 6 of the 8 diodes is about $1.8 \mathrm{~kW}$ (about $300 \mathrm{~W}$ per diode). The total amount of cooling water need to absorb the $3.1 \mathrm{MJ}$ of stored magnetic energy in the coupling magnet is about 20 liters (assuming a $40 \mathrm{C}$ rise in the water temperature and controlling the flow off of the cooling plate temperature.

One can reduce the voltages to ground and the layer-to-layer voltage by increasing the resistance of the resistors across the coils. If one increases the resistance across the coil in each sub-division to about 5 ohms, nearly half of the magnet stored-energy will end up in the resistor. For a coupling magnet is the flip mode, the stored energy per coil is about $1.55 \mathrm{MJ}$. If half of 
this energy ends up in the resistor, the mass must be about $8 \mathrm{~kg}$ per resistor (two per focusing magnet), in order for the resistor temperature not to end up above $80 \mathrm{C}$ at the end of the quench. To put some scale on the problem, 5-ohm resistor made from stainless steel that has a total mass of $8 \mathrm{~kg}$ will be 113-meters long with a cross-section area of 9.04 square millimeters. When the resistors remove half of the magnet from the circuit, the peak voltage to ground within the magnet drops to about $1250 \mathrm{~V}$ and the peak layer to layer voltage is less than $50 \mathrm{~V}$.

In the focusing magnet one doesn't need the quench protection resistors and diodes to be cold. Because the coil leads are brought out to room temperature, the quench protection diodes and resistors can be warm as well as cold. The lab G solenoid [14] built for Fermi lab is almost identical to the MICE focusing magnet. The length of the coils and the mandrel between the coils is $640 \mathrm{~mm}$, versus $620 \mathrm{~mm}$ for the MICE focusing magnet. The inner radius of the magnet coils is $260 \mathrm{~mm}$, versus $263 \mathrm{~mm}$ for the MICE focusing magnet. The amount of superconductor in the Lab G magnet is slightly less than the amount of superconductor for the MICE focusing magnet. The lab G magnet is shown in Figure 11.

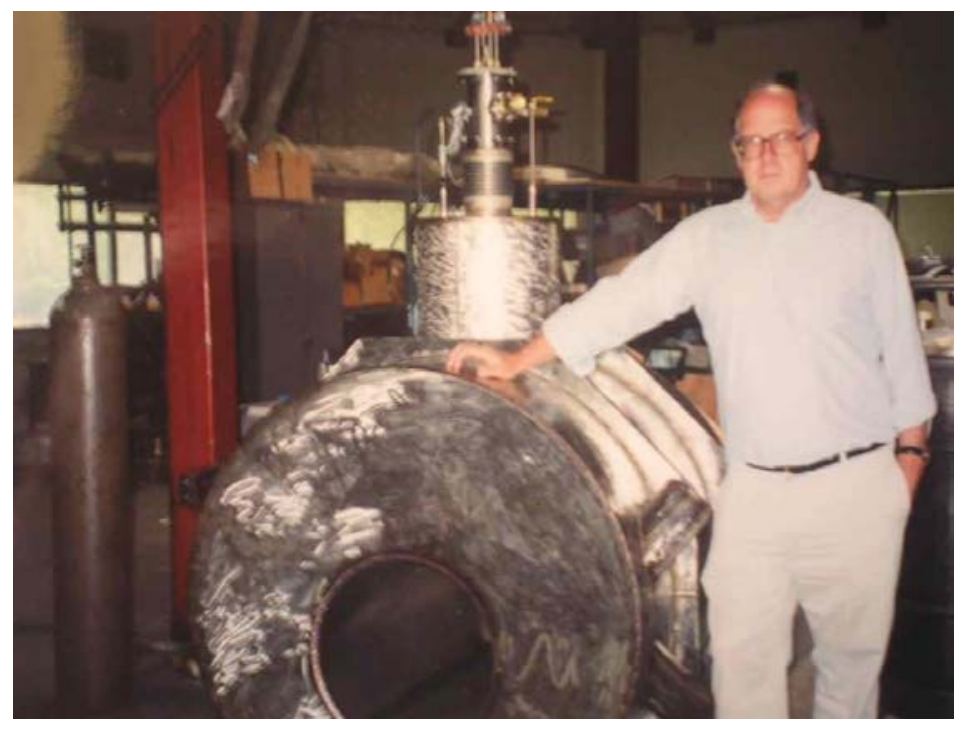

Figure 11. The Finished Lab G Magnet built for Fermilab in 1999

An important difference between the Lab G magnet and the MICE focusing magnet shown in Figure 9 is that the quench protection resistors and diodes are outside of the magnet cryostat at room temperature. The Lab G solenoid resistor extracts about 40 percent of the magnet storedenergy during a quench. An $8 \mathrm{~kg}$ resistor at room temperature $(293 \mathrm{~K}$ ) will end up at a temperature of $215 \mathrm{C}$ ( $488 \mathrm{~K}$ ) after the magnet quenches. If the resistor is enclosed and it can be air cooled, a final temperature of $215 \mathrm{C}$ is quite reasonable for stainless steel. If one wants the final resistor temperature to end up at $100 \mathrm{C}$, the 5-ohm resistor mass must be increased to $20 \mathrm{~kg}$.

Figure 12 shows how a quench protection system can be fabricated using room temperature resistors and diodes. If the forward voltage of the diode at $1 \mathrm{~mA}$ is one volt, the number of quench protection diodes per focusing magnet coil should be five or six, in order to prevent the quench protection system from shunting the magnet current while a single focusing magnet is being charged at $\pm 10 \mathrm{~V}$. The minimum number of quench protection diodes is four per focusing magnet coil. This will still allow the rapid discharge varistor shown in Figure 10 to be used for each focusing magnet. The charge voltage will be limited to \pm 7 volts per magnet. 


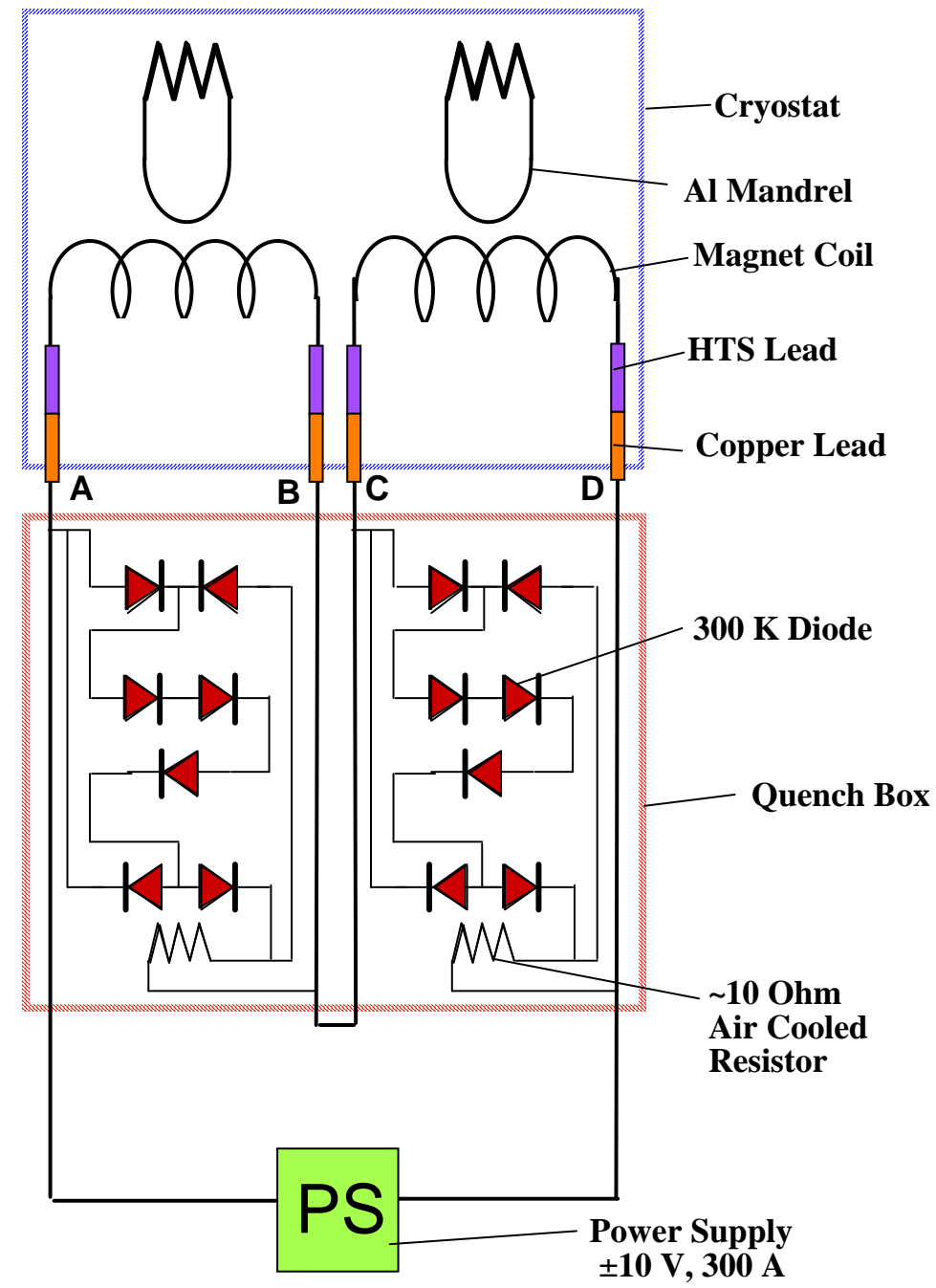

Figure 12. A Room Temperature Quench Protection System for a Focusing Magnet

Figure 12 shows a room temperature diode and resistor combination that has the diodes and resistor located in a quench protection system box that next to the magnet itself. If this magnet is to be charged at $\pm 10 \mathrm{~V}$, a minimum of 5 diodes (with a 1 volt forward voltage) is need per diode resistor circuit. A single diode will absorb about $600 \mathrm{~J}$ of energy during a magnet quench. Each resistor may absorb up to 500 kilojoules of energy during the quench process. This heat must be absorbed in the resistor. Air-cooling will cool the resistor back down to room temperature while the magnet is recovering from the quench. This method of quench protection was used on the Lab G magnet at Fermilab.

The resistor value is set to minimize the peak voltage in each focusing coil. The resistor also reduces the layer-to-layer voltage in the magnet as well. The problem with the quench protection system shown in Figure 12 is that quench protection resistors can be disconnected from the magnet while it is charged. Are must be taken to avoid disconnecting the quench protection resistors and diodes from the magnet. A method for preventing a disconnect of the external quench protection system from damaging the magnet is to put a two pair of back to pack diodes across the magnet leads at $4 \mathrm{~K}$. It can be argued that if one is going to do this, one may as well build the quench protection system shown in Figure 9. 


\section{The effect of the Rapid Discharge System on the Magnet Power Cables}

It is useful to look at the effect of the rapid discharge varistor systems on the cables used to connect the MICE magnets to the power supplies. First, the cables for superconducting magnets may be designed based on different criteria than cables for conventional water-cooled magnets. In a conventional water-cooled magnet circuit, the voltage drop in the cables that connect the power supply to the magnet is small compared to the voltage drop across the coils of conventional magnet. As a result, the size of conventional cables is determined by safety considerations (overheating due to IR losses) rather than voltage drop.

In a circuit that contains a superconducting magnet, the power supply supplies current to the magnet at a low voltage. The power supply voltage is set by the rate at which one wants to charge or discharge the magnet (the inductive voltage). MICE magnet power supplies provide a maximum current of $300 \mathrm{~A}$ at a maximum voltage of $\pm 10 \mathrm{~V}$ (a two quadrant supply). The correction power supplies for the end coils of the spectrometer solenoid provide a maximum current of $\pm 60 \mathrm{~A}$ at a maximum voltage of $\pm 5 \mathrm{~V}$ (a four quadrant supply). When the magnet is operating at its steady state current, there is no voltage drop across the coils. The voltage drop in the magnet circuit is the sum of the voltage drop along the leads that go into the magnet cryostat (about $90 \mathrm{mV}$ ), and the voltage drop along cables from the power supply to the magnet.

When the magnet is being charged or discharged, there is an inductive voltage across the superconducting coil. The voltage across the superconducting coil is proportional to the magnet inductance $\mathrm{L}$ and di/dt in the coil. The IR voltage drops in the magnet circuit must be added to the inductive voltages across the coil. When a magnet is being charged, the inductive voltage available to coil is the voltage generated by the power supply minus the IR voltage across the cables. When a magnet is being discharged, the discharge voltage across the coil is the voltage across the discharge circuit plus the IR voltage across the cables. The IR voltage increases the time needed to charge magnet, and it decreases the time needed to discharge the magnet. The addition of a rapid discharge varistor circuit further complicates the situation, depending on where the rapid discharge varistor system is located in the circuit.

The 300-A circuits for the MICE magnets have been designed so that at voltage drop along the cables shall be no more than $3 \mathrm{~V}$ when the cables carry $300 \mathrm{~A}$. The voltage drop along the cables is proportional to the current in the cables. From a safety standpoint, a 10 to 20 -volt drop along a long length of cable may be acceptable, but this voltage drop might be unacceptable for the MICE magnets, because there wouldn't be enough voltage to charge the magnets to full current. The 60-A circuits for the MICE spectrometer magnet are designed so that the cable voltage drop does not exceed $1.5 \mathrm{~V}$ when the cables carry a full current of $60 \mathrm{~A}$. The cables that connect the magnet to the power supply must meet safety requirements, but they also must meet the voltage drop requirements for the magnet power circuits.

Table 2 shows the set power supply voltage, the maximum allowable voltage drop along the cables, and the total circuit resistance as a function of the magnet circuit (There are three circuits in each tracker magnet; there is one circuit in each coupling and focusing magnet.) and the number of magnets that are in that circuit (depending on the stage of MICE). Table 3 shows the charging time for the magnet circuits and the discharge time for the magnet circuits using the rapid discharge circuit. The first column in Table 2 shows the magnet circuit and the maximum current that circuit should be designed for. The current shown in column one of Table 3 is the maximum operating current. The second column in Tables 2 and 3 shows the number of diodes in the varistor circuit given in Figures 4, 5, 8, and 10.

Table 2. The Power Supply Voltage Setting, the Cable Voltage Drop, and the Circuits Resistance for 
Each Magnet Circuit as a Function of the Number of Magnets in the Circuit

\begin{tabular}{|c|c|c|c|c|}
\hline \multirow[t]{2}{*}{$\begin{array}{l}\text { Magnet Circuit } \\
\text { Current } \mathbf{I}_{\mathbf{D}}\end{array}$} & \multirow[t]{2}{*}{$\begin{array}{c}\text { Number of } \\
\text { Varistor Diodes }\end{array}$} & \multicolumn{3}{|c|}{$\begin{array}{l}\text { Upper Limit of Power Supply Voltage }(\mathrm{V}) \\
\text { Voltage Drop in the Magnet Circuit a Current } I_{D}(\mathrm{~V}) \\
\text { Magnet Circuit Cable Resistance }(\mathrm{m} \Omega)\end{array}$} \\
\hline & & 1 Magnet & 2 Magnets & 3 Magnets \\
\hline \multirow{3}{*}{$\begin{array}{l}\text { Tracker MI } \\
\text { (300 A) }\end{array}$} & \multirow{3}{*}{3} & $2.9 \mathrm{~V}$ & $5.8 \mathrm{~V}$ & ---- \\
\hline & & $1.9 \mathrm{~V}$ & $3.0 \mathrm{~V}$ & ---- \\
\hline & & $6.33(\mathrm{~m} \Omega)$ & $10.0(\mathrm{~m} \Omega)$ & ---- \\
\hline \multirow{3}{*}{$\begin{array}{l}\text { Tracker M2 } \\
\text { (300 A) }\end{array}$} & \multirow{3}{*}{3} & $2.9 \mathrm{~V}$ & $5.8 \mathrm{~V}$ & ---- \\
\hline & & $1.9 \mathrm{~V}$ & $3.0 \mathrm{~V}$ & ---- \\
\hline & & $6.33(\mathrm{~m} \Omega)$ & $10.0(\mathrm{~m} \Omega)$ & ---- \\
\hline \multirow{3}{*}{$\begin{array}{l}\text { Spectrometer } \\
\text { (300 A) }\end{array}$} & \multirow{3}{*}{11} & $10 \mathrm{~V}$ & $10 \mathrm{~V}$ & ---- \\
\hline & & $2.0 \mathrm{~V}$ & $3.0 \mathrm{~V}$ & ---- \\
\hline & & $6.67(\mathrm{~m} \Omega)$ & $10.0(\mathrm{~m} \Omega)$ & ---- \\
\hline \multirow{3}{*}{$\begin{array}{l}\text { Coupling } \\
\text { (220 A) }\end{array}$} & \multirow{3}{*}{23} & $10 \mathrm{~V}$ & ---- & ---- \\
\hline & & $3.0 \mathrm{~V}$ & ---- & ---- \\
\hline & & $13.6(\mathrm{~m} \Omega)$ & ---- & ---- \\
\hline \multirow{3}{*}{$\begin{array}{l}\text { Focusing } \\
\text { (260 A) }\end{array}$} & \multirow{3}{*}{6} & $5.8 \mathrm{~V}$ & $10 \mathrm{~V}$ & $10 \mathrm{~V}$ \\
\hline & & $2.0 \mathrm{~V}$ & $2.5 \mathrm{~V}$ & $3.0 \mathrm{~V}$ \\
\hline & & $7.69(\mathrm{~m} \Omega)$ & $9.61(\mathrm{~m} \Omega)$ & $11.5(\mathrm{~m} \Omega)$ \\
\hline
\end{tabular}

Table 3, The Charge Time and Rapid Discharge Time for Each Magnet Circuit as a Function of the Number of Magnets in the Circuit

\begin{tabular}{|c|c|c|c|c|}
\hline \multirow{2}{*}{$\begin{array}{l}\text { Magnet Circuit } \\
\text { Current } \mathbf{I}_{M}\end{array}$} & \multirow{2}{*}{$\begin{array}{c}\text { Number of } \\
\text { Varistor Diodes }\end{array}$} & \multicolumn{3}{|c|}{$\begin{array}{l}\text { Magnet Circuit Charge Time (s) } \\
\text { Magnet Rapid Discharge Time (s) }\end{array}$} \\
\hline & & 1 Magnet & 2 Magnets & 3 Magnets \\
\hline \multirow{2}{*}{$\begin{array}{l}\text { Tracker MI } \\
(275 \mathrm{~A})\end{array}$} & \multirow{2}{*}{3} & $\sim 1550$ & $\sim 1410$ & ---- \\
\hline & & $\sim 730$ & $\sim 760$ & --- \\
\hline \multirow{2}{*}{$\begin{array}{l}\text { Tracker M2 } \\
\text { (275 A) }\end{array}$} & \multirow{2}{*}{3} & $\sim 710$ & $\sim 640$ & ---- \\
\hline & & $\sim 330$ & $\sim 345$ & ---- \\
\hline \multirow{2}{*}{$\begin{array}{l}\text { Spectrometer } \\
\text { (275 A) }\end{array}$} & \multirow{2}{*}{11} & $\sim 2260$ & $\sim 4800$ & ---- \\
\hline & & $\sim 1570$ & $\sim 1600$ & ---- \\
\hline \multirow{2}{*}{$\begin{array}{l}\text { Coupling } \\
\text { (213 A) }\end{array}$} & \multirow{2}{*}{23} & $\sim 14500$ & ---- & ---- \\
\hline & & $\sim 4620$ & ---- & ---- \\
\hline \multirow{2}{*}{$\begin{array}{l}\text { Focusing } \\
(250 \mathrm{~A})\end{array}$} & \multirow{2}{*}{6} & $\sim 2740$ & $\sim 5640$ & $\sim 8700$ \\
\hline & & $\sim 3260$ & $\sim 3430$ & $\sim 3490$ \\
\hline
\end{tabular}

From Tables 2 and 3 one can see that the magnets circuits can be designed so that the magnets can be charged in a reasonable time. The rapid discharge criteria for the magnets can also be met using the rapid discharge circuits shown in Figure 4, 5, 8, and 10. 
If one looks at the number of diodes in the circuit, one sees that the cable resistance reduces the number of diodes needed for the spectrometer coils, the coupling magnet and the focusing magnet. The number of diodes in the spectrometer coil rapid discharge circuit can be reduced from eleven to about nine and still achieve the desired discharge time of 1800 seconds. The actual circuit was built using eight diodes. This will increase the discharge time to 2000 seconds, which is still acceptable given the mass of the shields in the tracker magnet. The coupling magnet discharge circuit could have as few as 20 diodes in series and still achieve a discharge time of 5400 seconds. The focusing magnet rapid discharge circuit has the right diode number.

Before leaving the topic cable resistance and voltage drop it is worth looking at the resistance and current carrying capacity for various commercial cable sizes The examples here are given for American Standard Wire gauges sizes from 0 to 0000. Table 4 shows the copper cross-section area, the resistance per meter at $50 \mathrm{C}$, and the allowable Fire Underwriters Current capacity for modern insulations (other than rubber).

Table 4. Copper Cross-section Area, Cable Resistance per Meter, and Current Rating for ix Cable Sizes

\begin{tabular}{|c|c|c|c|}
\hline Cable Gauge & $\begin{array}{c}\text { Copper Area } \\
\left.\mathbf{( m m}^{\mathbf{2}}\right)\end{array}$ & $\begin{array}{c}\text { Resistance at } \\
\mathbf{5 0 ~ C} \\
\left(\mathbf{m} \boldsymbol{\Omega} \mathbf{~ m}^{-\mathbf{1}} \mathbf{)}\right.\end{array}$ & $\begin{array}{c}\text { Current Rating } \\
\text { (A) }\end{array}$ \\
\hline $\mathbf{0 0 0 0}$ & 107.2 & 0.180 & 325 \\
\hline $\mathbf{0 0 0}$ & 85.03 & 0.226 & 275 \\
\hline $\mathbf{0 0}$ & 67.43 & 0.286 & 225 \\
\hline $\mathbf{0}$ & 53.48 & 0.360 & 200 \\
\hline $\mathbf{1}$ & 42.41 & 0.454 & 150 \\
\hline $\mathbf{2}$ & 33.63 & 0.573 & 125 \\
\hline
\end{tabular}

From the table above one can determine the cable sizes need for the MICE magnets. When one looks at the location of the power supplies and the hookup pattern for the magnets, on may find that even 0000 cable may not adequate for use for some of the MICE magnet circuits. When one looks at the 60 A cable, a number two cable appears to be adequate from the standpoint of current carrying capacity, but it may not adequate from the standpoint of the cable resistance when it is used in MICE. It is worth pointing out that the Underwriters Laboratories current ratings may not be adequate for cables that are in tray with many other cables. The Fermilab standard calls for larger cables than are typically called for. 


\section{Some Concluding Comments}

A rapid discharge varistor system can be built for each of the three types of magnets needed in the MICE channel. The key to the rapid discharge varistor is using the forward voltage of the diodes that make up the varistor. The forward voltage of the diodes that make up the varistor must be less than the $1 \mathrm{~mA}$ forward voltage for the quench protection diodes. This means that the discharge voltage generated by the varistor and the magnet lead cables from the power supply to the magnets cannot exceed 4 volts for every cold diode that is in the magnet quench protection system. Silicon power diodes that are at $4 \mathrm{~K}$ have about eight times the forward voltage of the same diodes at $300 \mathrm{~K}$. In general, the thickness of the diode junction determines its forward voltage at any temperature.

The varistor system for the tracker solenoid is designed to discharge the magnet in about 1800 seconds. Each of the two tracker magnet coil systems has its varistor system. When the two tracker magnets are connected in series, the two varistor-systems are also connected in series. Each coupling magnet has its own power supply and varistor system. The coupling magnet varistor system is designed to discharge the magnet is about 5400 seconds. The three focusing magnets are designed to be connected in series during stage 6 of MICE. The varistor system for the focusing magnet is designed to discharge the magnet in about 3600 seconds. Each focusing magnet has its varistor system. When focusing magnets are connected in series, the varistor-systems are also connected in series.

The varistor systems must be cooled during a magnet discharge. The MICE tracker magnet varistor systems as built are water-cooled. During a power failure, there is no pumping to deliver water to the varistor diode cooling plates. Water must be delivered from the mains or it must come from a header tank on the roof of the MICE hall that is filled with about 1000 liters of treated water. The water flow must be controlled during the magnet discharge.

Other magnets in MICE may choose to use air-cooled diodes, but extra space on the MICE floor must be allotted for the air-cooling boxes. Air-cooled diodes must be cooled by natural convection because there is not fan power available during a power failure. An advantage of aircooled diode is that they don't require not water source during a power shut down.

The diodes must be arranged so that the magnet can be charged and discharged in any polarity. It is common that quench protection diodes be back-to-back diodes (one pair of diodes per diode needed in in the quench protection circuit). Back-to-back diodes require two diodes for each diode needed in the forward direction. Varistor circuits can be arranged using back-to-back diodes as well. If 20 diodes are needed in one-direction in a back-to-back circuit, 40 diodes must be used to allow the circuit to go both directions. This report shows that the diodes in the varistor circuit can be arranged so that they operate in both directions without having to resort to back-toback diodes. A varistor circuit can be arranged so that it will operate in both directions with two more diodes than are needed to operate in one direction alone. If 20 diodes are needed in one direction, one can make the circuit operate in both directions by using 22 diodes.

The quench protection systems for the three types of MICE magnets were designed using cold-diodes. Since most of the MICE magnet coil circuits have more than one sub-division per magnet circuit, back-to-back diodes are used for each of these sub-divisions. The focusing magnet, which has a pair of warm leads for each coil can be quench protected using warm diodes and resistors. The same statement is true for the two match coils in the tracker solenoids, but the magnets as fabricated have cold quench protection diodes. For safety reasons, cold diodes are probably required to keep the coil voltages low in the event the magnet coil is disconnected. 
The resistance of the cables that connect the MICE magnets is important. At $300 \mathrm{~A}$, the voltage drop for most of the magnet circuits for MICE must be less than $3 \mathrm{~V}$. The circuits for coils M1 and M2 must have a voltage drop that is lower because of limits imposed by the rapid discharge circuit. Cable resistance and voltage drop are important because the MICE magnets are superconducting and the power supply voltage for the 300 A supply is only 10 volts.

\section{Acknowledgements}

This work was also supported by the Office of Science, United States Department of Energy, under DOE contract DE-AC02-05CH11231. DOE funding for the US Neutrino Factory and Muon Collider Collaboration is also gratefully acknowledged.

\section{References}

[1] G. Gregoire, G. Ryckewaert, L. et al, "MICE and International Muon Ionization Cooling Experiment Technical Reference Document,” http://hep04.phys.iit.edu/cooldemo/notes (October 2004)

[2] M. A. Green, “The Superconducting Solenoids for the MICE,” LBNL Report LBNL-51920, December. 2002, MICE Note 58, http://hep04.phys.iit.edu/cooldemo/notes

[3] M. A. Green, L. Wang, X. L. Gou, F. Y. Xu, and L. X. Jia, "Quench Protection for the MICE Cooling Channel Coupling Magnet,” LBNL Report LBNL-63698, (2007), MICE Note 193, http://hep04.phys.iit.edu/cooldemo/notes

[4] M. A. Green, "The Effect of the Magnetic Field on HTS Leads What Happens when the Power Fails at RAL,” LBNL-62458, MICE Note 162, http://hep04.phys.iit.edu/cooldemo/notes, (2007)

[5] S. Yamamoto, T. Yamada, and M. Iwamoto, "Quench Protection of Persistent Current Switches using diodes in Cryogenic Temperature,” PESC 88’ Record, p 321, CH 25239/88, April 1988

[6] V. Berland, D. Hagedorn, and F. Rodrigues-Marcos, "Testing of High Current By-pass Diodes for the LHC Quench Protection,” IEEE Transactions on Magnetics 32, No. 4, p 3094, (1996)

[7] The Effect of Magnetic Field on the DT-400 Series of Silicon Temperature Diodes. Lake Shore Cryotronics Inc. web-site http://www.lakeshore.com

[8] D. Hagedorn and E. Floch, "Protection of Superconducting Pulsed Magnets for Accelerators," a talk given at ECOMAG-25, Frascati Italy, 25 to 28 October 2005

[9] M. A. Green, C. Y. Chen, T. Juang W. Lau, C. Taylor, S. P. Virostek, R. Wahrer, S. T. Wang, H. Witte, and S. Q. Yang, "Design Parameters for the MICE Tracker Solenoid,” IEEE Transactions on Applied Superconductivity 17, No. 2, p 1247, (2007), LBNL-61383, MICE Note 158

[10] M. A. Green and S. P. Virostek, "The Dimensions and Number of Turns for the Tracker Solenoids As-built compared to the Original Magnet Design,” MICE Note 207, (2008)

[11] L. Wang, M. A. Green, F. Y. Xu et al, "The Engineering Design of the 1.5-m Diameter Solenoid for the MICE RF Coupling Coil Modules,” IEEE Transactions on Applied Superconductivity 18, No. 2, p 937, (2008), LBNL-63481, MICE Note 187, http://hep04.phys.iit.edu/cooldemo/notes

[12] M. A. Green, L. Wang, and X. L. Gou, "Quench Protection for the MICE Channel Coupling Magnet,” LBNL-63698, MICE Note 193, http://hep04.phys.iit.edu/cooldemo/notes

[13] M. A. Green and H. Witte, Quench Protection and Power Supply Requirements for the MICE Focusing and Coupling Magnets,” MICE Note 114, http://hep04.phys.iit.edu/cooldemo/notes, LBNL-57580, June 2005

[14] M. A. Green, J. Y. Chen, and S. T. Wang, "The Design, and Construction of a Gradient Solenoid for the High Power RF Cavity Experiment for the Muon Collider," Institute of Physics Conference Series 167, p 1199, (2000), LBNL-44188 


\section{DISCLAIMER}

This document was prepared as an account of work sponsored by the United States Government. While this document is believed to contain correct information, neither the United States Government nor any agency thereof, nor The Regents of the University of California, nor any of their employees, makes any warranty, express or implied, or assumes any legal responsibility for the accuracy, completeness, or usefulness of any information, apparatus, product, or process disclosed, or represents that its use would not infringe privately owned rights. Reference herein to any specific commercial product, process, or service by its trade name, trademark, manufacturer, or otherwise, does not necessarily constitute or imply its endorsement, recommendation, or favoring by the United States Government or any agency thereof, or The Regents of the University of California. The views and opinions of authors expressed herein do not necessarily state or reflect those of the United States Government or any agency thereof, or The Regents of the University of California. 